\title{
Exploring Dynamics of PRODYs with International Trade Data
}

\author{
Tieju Ma
}

\begin{abstract}
Economists have used the concept of PRODYs to evaluate the added values to different traded products. Are PRODYs of products relatively constant or keeping changing? Little work has been done to answer this question. This study uses the International Trade Data from 1984 to 2010 to explore the dynamics of PRODYs. For a product, its PRODY is usually calculated as the weighted GDP per capital of countries who export the product. With the increase of most countries GDPs per capital, PRODYs of most products tends to increase. We created the PRODY-order data set for every year from 1984 to 2010, and found different dynamic patterns. Some products' PRODY-orders tend to increase and some tend to decrease. This study implies when doing international comparisons, people should be careful that products' relative PRODYs (PRODY-orders) could be changing.
\end{abstract}

Index Terms-International trade data, PRODY, dynamics, products, SITC4.

\section{INTRODUCTION}

Economists have tried to compare countries' export sophistications with International Trade Data [1]-[4]. Most of such comparisons use the PRODYs of products exported by a country to evaluate the country's level of export sophistications, or simply EXPYs. A product's PRODY is calculated as the weighted GDP per capital of countries who export the product [1], [5]. So a product's PRODY can be view as the product's associated income level [6]. Economists have paid a lot of attentions to the dynamics of countries EXPYs [7]-[11], little work has been found to discuss the dynamics of PRODY. Are PRODYs of products relatively constant or keeping changing? This questions remain open in literatures although economists may have noticed the dynamics of PRODYs when they were using them to calculate EXPYs.

This study uses the International Trade Data from 1984 to 2010 to explore the dynamics of PRODYs. With the increase of most countries GDPs per capital, PRODYs of most products tends to increase. We created the PRODY-order data set for every year from 1984 to 2010, and found different dynamic patterns. Some products' PRODY-orders tend to increase and some tend to decrease. This study implies when doing international comparisons, people should be careful that products' relative PRODYs (PRODY-orders) could be changing

The rest of the paper is organized as follows. Section II introduces the methods of calculating PRODYs and generating PRODY-orders. Section III introduces the data source we used in the calculations. Section IV presents the dynamics of PRODYs and PRODY-orders. Section V gives concluding remarks.

\section{The Method of CAlculating PRODYS AND Their ORDERS}

We adopted the method put forward by Hausmann et al. [1] to calculate PRODYs. In this method, PRODY is calculated with Eq. 1.

$$
\operatorname{PRODY}_{k}^{t}=\sum_{j=1}^{J} \frac{\left(x_{j k}^{t} / X_{j}^{t}\right)}{\sum_{j=1}^{J}\left(x_{j k}^{t} / X_{j}^{t}\right)} Y_{j}^{t}
$$

where products are indexed with $k$ and countries/areas are indexed with $j, x_{j k}^{t}$ denotes the export of product $k$ from country $j$ at time $t, X_{j}^{t}$ denotes the total export of country/area $j$ at time $t, Y_{j}^{t}$ denotes the per capital GDP of country/area $j$ at time $t$, and $J$ denotes the total number of countries/areas.

With Eq. (1), we calculate all products' PRODYs using the per capital GDPs measured in both market exchange rate and in PPP (purchasing power parity) from 1984 to 2010. After calculating the PRODYs of all products for each year, we did locally weighted scatter plot smooth using least squares quadratic polynomial fitting with the span as the 27 years and the smooth was resistant to outliners.

For each year from 1984 to 2010 , we sort the smoothed PRODYS, denoted as $P R O D Y_{k}{ }^{\prime}$, in descending order to generate a data set which contains each product's order in each year. Then we explore the dynamics of $\operatorname{PRODY_{k}^{t}}$ and each product's order in time dimension.

\section{DATA SOURCE}

In this study, the international trade data are from Huasmman and Hidalgo's study on Economic Complexity [3] (http://atlas.media.mit.edu/) which are originally from United Nations Commodity Trade Statistics Database research isipt received December 15, 2014; revised May 5, 2015. This 71125002), and all shortcoming remains to the author.

Tieju Ma is with the School of Business, East China University of Science and Technology, Meilong road 130, Shanghai, 200237, China. He is also with the International Institute for Applied Systems Analysis, Schlosplatz 1 A-2361 Laxenburg, Austria (e-mail: tjma@ecust.edu.cn, ma@ecust.edu.cn). 
(COMTRADE). We use the International Trade Data from 1984 to 2010, classified with the 4-digit level of Standard International Trade Classification (revision 2). The countries/areas in the trade data are different in different year. Some countries divided into several, for example, the former Soviet Union. Some countries merged together, for example, the East Germany and the West Germany.

The per capital GDPs of countries/areas measured in MER (market exchange rate) are mainly from United Nations Statistics

Division (http://unstats.un.org/unsd/snaama/dnllist.asp). The per capital GDPs from United Nations do not match the international trade data very well. From example, the international data of Czechoslovakia is available from 1984 to 1992, while the per capital GDPs of Czechoslovakia is only available from 1984 to 1990 . When there is mismatch of the two data sets, we always keep the international trade data and tried to find the corresponding per capital GDPs from other resources such as CIA World Fact book (https://www.cia.gov/library/publications/the-world-factboo $\mathrm{k} /$ ) or estimate missing data with different schemes. A detailed description of how per capital GDPs measured in market exchange rate are filled up can be required from the author.

The per capital GDPs of countries/areas measured in PPP are mainly from Penn World Table (http://www.ggdc.net/pwt). The per capital GDPs in PPP from Penn World Table do not match the international trade data exactly. For those countries who are available in the international trade data but have no corresponding data in Penn World Table, we use the MER/PPP ratio (which can be calculated with the GDP data of countries both available in United Nations Statistics Division and Penn World Table) to convert the country's per capital GDP in MER to its per capital GDP in PPP.

\section{DYNAMICS OF PRODYS AND THEIR ORDERS}

There are 781 kinds of products with the 4-digit SITC codes from 1984 to 2010. Fig. 1 plots the smoothed PRODYs of all products with the per capital GDPs in Eq. (1) measured in MER. Fig. 2 plots the smoothed PRODYs of all products with the per capital GDPs in Eq. (1) measured in PPP. As we can see from the two figures, from 1984 to 2010, for most of the products, their PRODYs increase. This is because from 1984 to 2010, for most of countries, their per capital GDPs measured in both MER and PPP increase.

In order to understand the competition among products in terms of their added values, we sort the smoothed PRODYS in descending order to generate a data set which contains each product's order in each year. All the 781 products are grouped into 10 groups with the first digit SITC codes denoted as $0,1, \ldots, 9$.

Table I shows all the 11 kinds of products in the second group. Fig. 3 shows the dynamics of PRODY orders of all the 11 kinds of products in the second group with per capital GDP measured in MER, and Fig. 4 shows those with per capital GDP measured in PPP. As we can see from Fig. 3 and Fig. 4, there are various dynamics of PRODY orders. Some products' orders decrease and some increase. PRODY orders in other group also have these dynamics.

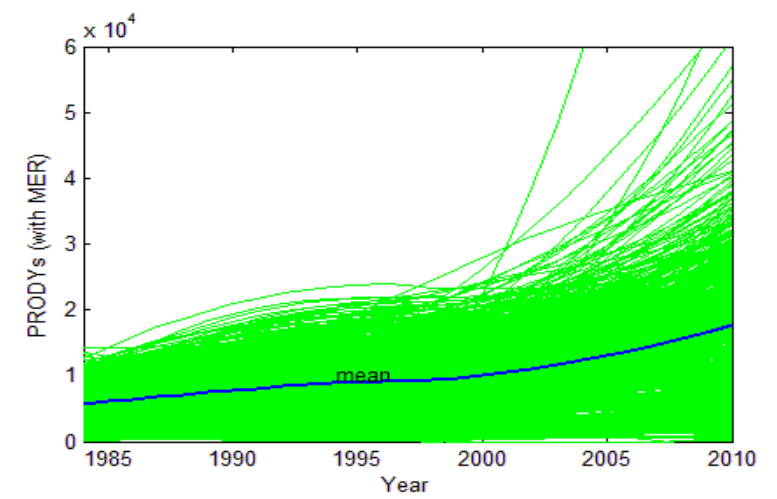

Fig. 1. Dynamics of PRODYs calculated with per capital GDP in MER.

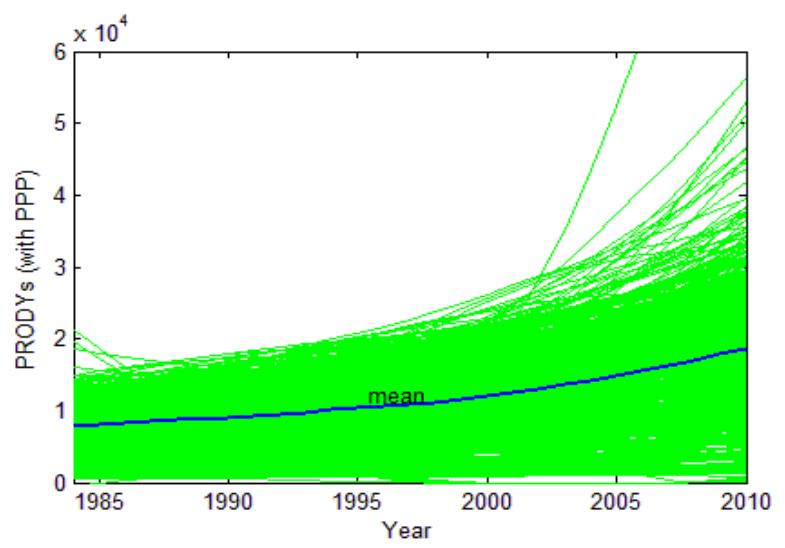

Fig. 2. Dynamics of PRODYs calculated with per capital GDP in PPP.

TABLE I: PRODUCTS AND THEIR 4-DIGIT LEVEL SITC IN THE 2ND GROUP Products SITC4

\begin{tabular}{ll} 
Non-alcoholic beverages N.E.S. & 1110 \\
Wine & 1121 \\
Fermented beverages & 1122 \\
Beer & 1123 \\
Alcoholic beverages & 1124 \\
Unstripped tobacco & 1211 \\
Wholly or partly stripped tobacco & 1212 \\
Tobacco refuse & 1213 \\
Cigars & 1221 \\
Cigarretes & 1222 \\
Tobbacco, extract, essences \& manufactures & 1223 \\
\hline
\end{tabular}

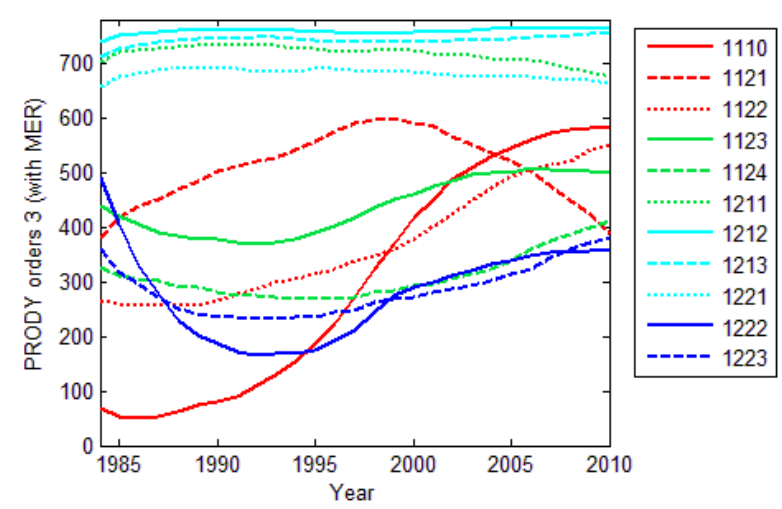

Fig. 3. Dynamics of PRODY orders of the second group calculated with per capital GDP in MER. 
Table II shows all the 16 kinds of products in the 4th group. Fig. 5 shows the dynamics of PRODY orders of all the 16 kinds of products in the 4th group with per capital GDP measured in MER, and Fig. 6 shows those with per capital GDP measured in PPP. As we can see from Fig. 5 and Fig. 6, there are various dynamics of PRODY orders. Some products' orders decrease and some increase. PRODY orders in other group also have these dynamics.

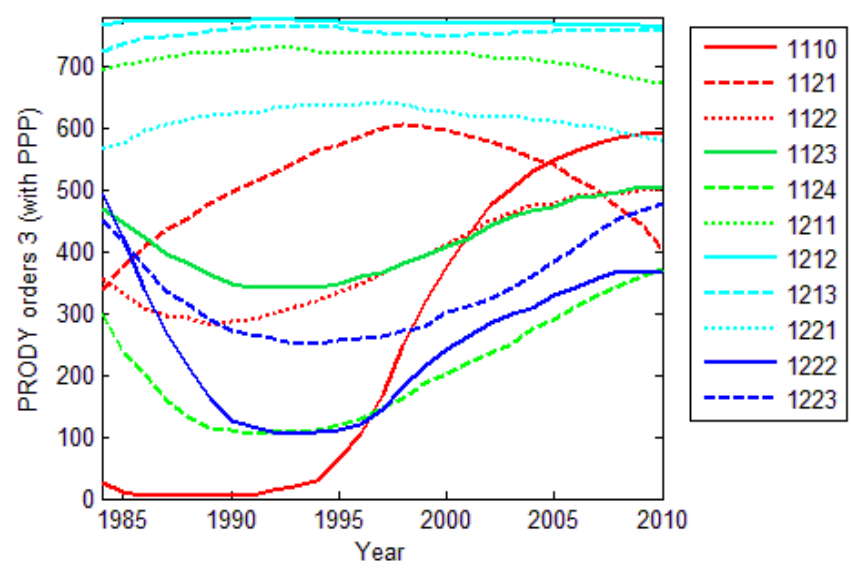

Fig. 4. Dynamics of PRODY orders of the second group calculated with per capital GDP in PPP.

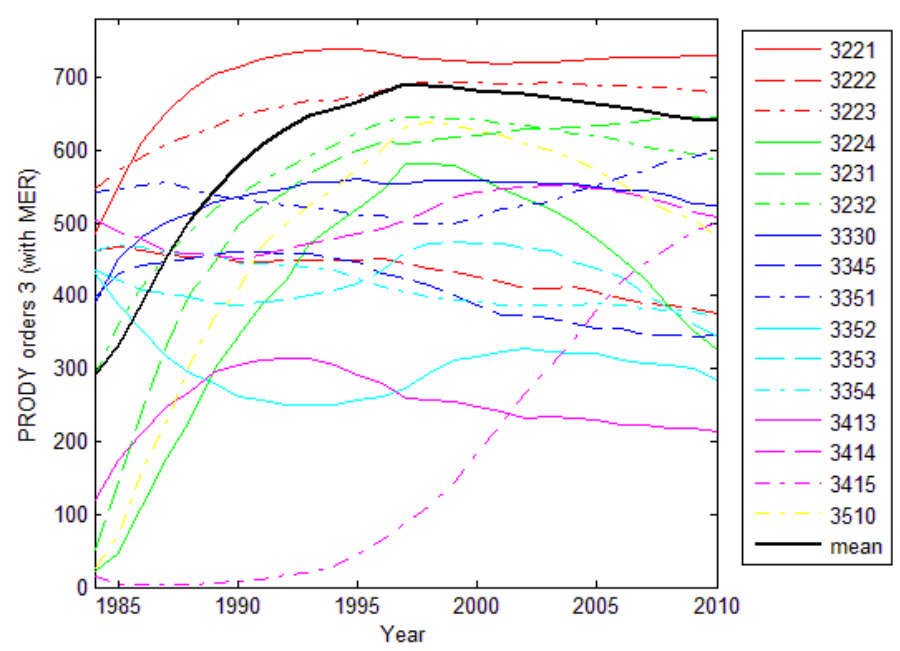

Fig. 5. Dynamics of PRODY orders of the fourth group calculated with per capital GDP in MER.

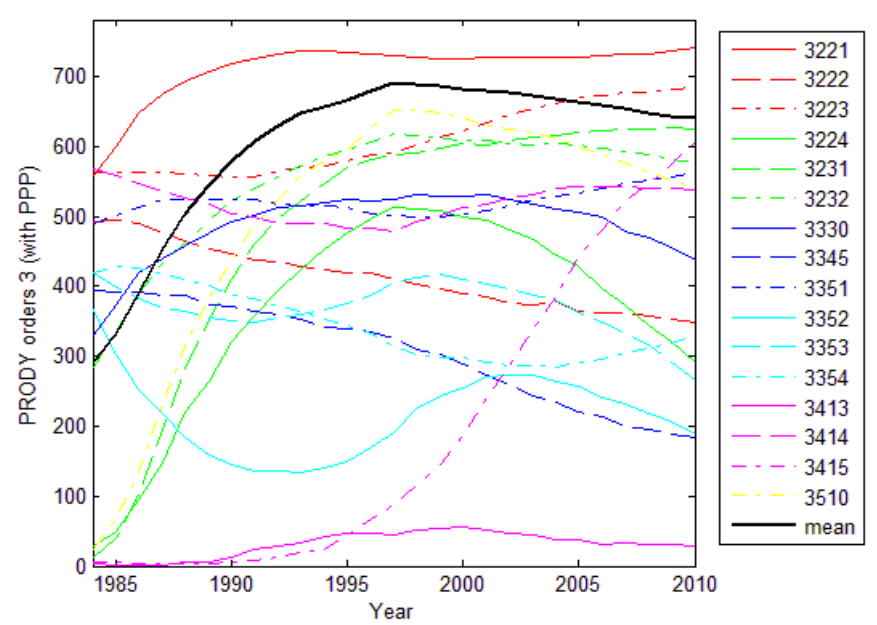

Fig. 6. Dynamics of PRODY orders of the fourth group calculated with per capital GDP in PPP.
Fig. 3-Fig 6 tell us that the relative per capital GDP levels associated with products are changing. What are the underlying mechanisms for these changing remain as our future research.

\begin{tabular}{lc} 
TABLE II: PRODUCTS AND THEIR 4-DigIT LEVEL SITC IN THE 4TH GROUP \\
\hline \hline Products & SITC4 \\
\hline Anthracite & 3221 \\
Other coal & 3222 \\
Lignite & 3223 \\
Peat & 3224 \\
Solid fuels & 3231 \\
Coke \& semi-coke of coal & 3232 \\
Crude petroleum & 3330 \\
Lubricating petroleum oils N.E.S. & 3345 \\
Petroleum jelly \& mineral waxes & 3351 \\
Mineral tars & 3352 \\
Mineral tar pitch & 3353 \\
Petroleum bitumen N.E.S. & 3354 \\
liquified hydrocarbons & 3413 \\
petroleum gases & 3414 \\
Coal \& water gases & 3415 \\
Electric current & 3510 \\
\hline \hline
\end{tabular}

\section{CONCLUding REMARKS}

This study calculated the PRODYs using the International Trade Data as well as per capital GDP both in MER and PPP from 1984 to 2010 . The study found that with the increase of most countries GDPs per capital either in MER or PPP, PRODYs of most products tends to increase. For exploring the competition among products in terms of their added values, this study created the PRODY-order data set for every year from 1984 to 2010 and found different dynamic patterns in PRODY orders, which implies that the relative per capital GDP levels associated with products are changing. In our future work, we will study the underlying mechanisms for these changing.

\section{REFERENCES}

[1] R. Hausmann, J. Hwang, and D. Rodrik, "What you export matters," Journal of Economic Growth, vol. 12, no. 1, p. 25, 2007.

[2] C. A. Hidalgo and R. Hausmann, "The building blocks of economic complexity," PNAS, vol. 106, no. 26, pp. 10570-10575, 2009.

[3] R. Hausmann, C. A. Hidalgo, S. Bustos, M. Coscia, A. Simoes, and M. A. Yildirim, The Atlas of Economic Complexity: Mapping Paths to Prosperity, Cambridge, USA: The MIT Press, 2013.

[4] C. A. Hidalgo, B. Klinger, A. L. Barabasi, and R. Hausmann, "The product space conditions the development of nations," Science, vol. 317, pp. 482-487, 2007.

[5] M. Michaely, Trade, Income Levels, and Dependence, Amsterdam: North-Holland, 1984.

[6] P. Klimek, R. Hausmann, and S. Thurner, "Empirical confirmation of creative destruction from world trade data," PLoS One, vol. 7, no. 6, 2012.

[7] J. Jarreau and S. Poncet, "Export sophistication and economic growth: Evidence from China," Journal of Development Economics, vol. 97, pp. 281-292, 2012. 
[8] Y, Nyarko, "Sustaining high economic growth in Sub-Saharan Africa: Knowledge and the structure of the economy," Journal of African Economies, vol. 22, pp. 77-101, 2013.

[9] E. Weldemicael, "Technology, trade costs and export sophistication," The World Economy, pp. 14-41, 2014.

[10] B. Xu, "The sophistication of exports: Is China special," China Economic Review, vol. 21, pp. 482-493, 2010.

[11] S. J. Zhu and X. L. Fu, "Drivers of export upgrading," World Development, vol. 51, pp. 221-233, 2013.

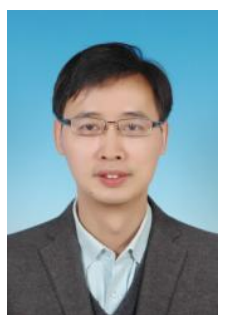

Tieju Ma was born in 1975 at Changzhou, Jiangsu Province, China. He received his bachelor's degree in industrial engineering in 1998 from Dalian University of Technology, China and from the same university, he received his master's degree in systems engineering in 2000. In October 2003, he received his $\mathrm{PhD}$ degree in knowledge science from the Japan Advanced Institute of Science and Technology.
Dr. Ma is currently a professor at the School of Business, East China University of Science and Technology, Shanghai, China. He is also a research scholar in the Transition to New Technology Program, International Institute for Applied Systems Analysis (IIASA). His research interest include modeling on technology (especially energy technology) transitions considering uncertainty, technological learning, and heterogeneous agents. 